\title{
Mycoplasma pneumoniae: acute illness, antibiotics, and subsequent pulmonary function
}

\author{
A R SABATO, A J MARTIN, B P MARMION, T W KOK, AND D M COOPER \\ Pulmonary Medicine Unit, Adelaide Children's Hospital, and Institute of Medical and Veterinary Science, \\ University of Adelaide, Australia
}

SUMMARY One hundred and eight children presenting with Mycoplasma pneumoniae infection were assessed during the acute illness and followed for three years. The incidence of wheezing with the acute infection ( $40 \%$ ) was greater than expected in a normal childhood population. The initial illness precipitated wheezing for the first time in some subjects but others wheezed only with the acute illness. In non-asthmatic subjects significant bronchodilator responsiveness was present one month after infection. Children given erythromycin during the first seven days of their illness had a significantly shorter fever duration compared with those treated inappropriately. No significant effects of treatment were noted on pulmonary function three years later but non-asthmatic children had abnormal mean forced expiratory volume in one second and forced expiratory flow after $50 \%$ of the expired vital capacity compared with 64 healthy controls. These findings indicate impaired function three years after initial infection.

Mycoplasma pneumoniae has been recognised as a cause of 'atypical pneumonia' since $1944^{1}$ and the organism was characterised as a mycoplasma in the 1960 s. $^{2}$ Although present endemically throughout the world, slowly evolving epidemics occur every few years. The last such epidemic in Adelaide was in 1978-79.

After infection with $M$ pneumoniae a transient increase in airways lability has been described ${ }^{34}$ in adults. One study, in children, has shown transient deterioration in lung function ${ }^{5}$ while another has indicated that airways function may be impaired over a prolonged period. ${ }^{6}$

There is doubt about the effectiveness of antibiotic treatment of $M$ pneumoniae in children, although tetracycline has been shown to have benefits in adults. ${ }^{89}$

The purpose of this study was to document the short and long term effects of $M$ pneumoniae on pulmonary function and the effect of antibiotic treatment on the acute infection, and to determine the influence of antibiotic treatment on long term pulmonary function.

\section{Subjects and method}

The survey covered 108 children with lower respiratory tract infection caused by $M$ pneumoniae who presented to The Adelaide Children's Hospital between April 1978 and March 1979. Complement fixation titres were equal to or greater than $1: 160$ in all cases and the children were aged between $1 \cdot 1$ years and $15 \cdot 8$ years.

Forty nine children, whose parents consented to further study were examined immediately with regard to the respiratory system, and pulmonary function tests were obtained at one, three, and six months and three years after the onset of the infection. Information, supplemented from a questionnaire, was obtained personally by one of the authors (ARS) soon after the infection and another clinical questionnaire was completed at three years. A history of respiratory symptoms between the initial illness and the three year follow up period was noted.

Forty two of the 49 children had a complement fixation titre of $1: 320$ or more, or a fourfold rise in titre. A titre equal to $1: 160$ associated with cold agglutinin titres of greater than or equal to 1:64 occurred in the other seven. Several children who were noted to have serological evidence of a second concurrent respiratory pathogen were excluded.

Follow up pulmonary function tests were performed only in children who had been free of respiratory tract symptoms during the preceding two weeks. Three or more complete pulmonary function 
examinations were performed in 43 of the 49 children. Pulmonary function studies were carried out with the patient standing. Maximum expiratory flow volume curves were obtained with an OHIO 842 spirometer and the curves were displayed on a Hewlett-Packard 7041 A X-Y recorder. Forced vital capacity, forced expiratory volume in one second, and their ratio; peak expiratory flow rate; and forced expiratory flow measured after $50 \%$ and $75 \%$ of the expired vital capacity were all derived from the curve. A maximum expiratory flow volume curve was also obtained after an inhaled dose of salbutamol. The results of pulmonary function in the study group were compared with those of 64 healthy children (laboratory controls) with a mean age of $10 \cdot 2$ years. The laboratory controls were recruited from the children of hospital personnel. Only those subjects who had no past respiratory history were included in this group.

Data from 36 of the 108 children were examined for efficacy of antibiotic treatment. Children not given an antibiotic were excluded as were those given erythromycin treatment after seven days from the onset of the respiratory illness. Seventeen of the 36 received erythromycin $(40 \mathrm{mg} / \mathrm{kg} /$ day for seven to 10 days). The remaining 19 received either penicillin, amoxycillin, or trimethoprim-sulphamethoxazole only-all having no in vitro activity against $M$ pneumoniae. ${ }^{10}$ Children with prolonged wheezing alone diagnosed as having $M$ pneumoniae were also excluded.

Fisher's exact test and Student's $t$ test were used to examine statistical differences.

\section{Results}

The incidence of wheezing in the initial 108 children during the acute illness was $40 \%$. All children recovered and $48(42 \%)$ were followed over the next three years. Thirty three of these $(69 \%)$ were non-asthmatics, although four children wheezed with the acute illness but had not wheezed before or after the illness. Ten children $(21 \%)$ had wheezed before the $M$ pneumoniae illness and five $(10 \%)$, who first wheezed with $M$ pneumoniae, wheezed subsequently. The mean age of this group was $8 \cdot 2$ years (range 4.5 to 13.75 years) and the ratio of boys to girls was 1.7 to 1 .

The results of pulmonary function tests in 33 non-asthmatic children were then compared with those of the laboratory controls. At one month after the clinical illness the mean percentage change in baseline forced expiratory volume in one second after inhaled salbutamol, as a function of the predicted value compared with the mean value for the laboratory controls, was significantly greater
$(\mathrm{P}<0.01$, mean (SD) $9.4 \% \quad(4.9 \%)$ for nonasthmatics and $(3.6 \%)(3.8 \%)$ for controls) but there were no significant differences at three and six months, and at three years. Mean forced vital capacity was consistently and significantly less than the laboratory controls' mean values at one month $(\mathrm{P}<0.05)$, three months $(\mathrm{P}<0.02)$, and three years $(\mathrm{P}<0.01)$. Mean forced expiratory volume in one second was significantly less than the control mean value $(\mathrm{P}<0.01)$ at one month but no other significant differences were detected at one, three, and six months. At three years, mean forced expiratory volume in one second $(\mathrm{P}<0.02)$ and forced expiratory flow after $50 \%$ of the expired vital capacity $(P<0.05)$ were significantly less than control mean values (Table 1).

The results in the 10 children who had wheezed before the onset of acute infection and the five children who had subsequently wheezed (classified also as asthmatics) were also compared with control values. Significant differences in mean values of all parameters except forced vital capacity were noted at one month, three months, and three years but no significant differences were noted at six months.

Patients treated with erythromycin (appropriately treated) and those treated with other antibiotics (inappropriately) were compared. The groups were comparable for age, boy to girl ratio, inpatient to outpatient ratio, and degree of radiological involvement. No significant differences for duration of cough, hospital stay, and length of radiological resolution were noted, but the mean length of duration of fever in the appropriately treated group compared with the inappropriately treated group was significantly less (Table 2 ).

Ten of the 33 non-asthmatic children followed for three years had received inappropriate treatment, 12 had received erythromycin after seven days, and 11 had received erythromycin before seven days. No

Table 1 Lung function results three years after infection with Mycoplasma pneumoniae (Mean (SD))

\begin{tabular}{lccl}
\hline $\begin{array}{l}\text { Pulmonary function } \\
\text { parameter }\end{array}$ & Non-asthmatics & Controls & \\
\hline FVC & $93.1(10.5)$ & $100.8(11.5)$ & $\mathrm{P}<0.01$ \\
FEV $_{1}$ & $94.5(11.7)$ & $100.6(10 \cdot 8)$ & $\mathrm{P}<0.02$ \\
FEV $_{1}$ FVC ratio & $89.7(7.2)$ & $89.2(5.1)$ & NS \\
PEFR $_{\text {FEF }_{50}}$ & $98.3(15.6)$ & $103.3(14.8)$ & NS \\
FEF $_{75}$ & $94.4(18.5)$ & $102.7(17.8)$ & $\mathrm{P}<0.05$ \\
$\%$ change in FEV & $95.5(31.2)$ & $103.6(24.9)$ & NS \\
\hline
\end{tabular}

$\mathrm{FVC}$ = forced vital capacity; $\mathrm{FEV}_{1}=$ forced expiratory volume in one second; PEFR = peak expiratory flow rate; $\mathrm{FEF}_{50}$ and $\mathrm{FEF}_{75}=$ forced expiratory flow measured after $50 \%$ and $75 \%$ of the expired vital capacity. Results expressed as per cent predicted (from control regression equations). $\mathrm{FEV}_{1}: \mathrm{FVC}$ ratio expressed as absolute values. $P$ is probability of values being significantly different from control group. NS $=$ not significant. 
Table 2 Effects of treatment

\begin{tabular}{lcc}
\hline Category & $\begin{array}{l}\text { Appropriate treatment } \\
\text { (erythromycin before }\end{array}$ & Inappropriate treatment \\
\hline Age (years). Mean (SD) & $8 \cdot 1(3 \cdot 7)$ & $7 \cdot 6(2 \cdot 4)$ \\
Boys:girls & $1 \cdot 7: 1$ & $1 \cdot 8: 1$ \\
Illness severity (inpatient/outpatient ratio) & $2 \cdot 2: 1$ & $3 \cdot 8: 1$ \\
Radiological severity ratio of mild to moderate or severe changes & $1 \cdot 5: 1$ & $1 \cdot 6: 1$ \\
Length of hospital admission (days). Mean (SD) & $5 \cdot 0(4 \cdot 1)$ & $6 \cdot 7(3 \cdot 2)$ \\
Duration of fever (days). Mean (SD) & $4 \cdot 7(1 \cdot 8)$ & $7 \cdot 3(3 \cdot 1)$ \\
Duration of cough (days). Mean (SD) & $24 \cdot 8(11 \cdot 4)$ & $\mathrm{NS}$ \\
Duration of radiological change (days). Mean (SD) & $28 \cdot 2(14 \cdot 8)$ & $\mathrm{NS}$ \\
\end{tabular}

significant differences were noted in mean pulmonary function values between these groups at the three year follow up. Numbers in each group who had pulmonary function studies performed at one, three, and six months were too small for useful analysis.

\section{Discussion}

Although 108 children were initially selected by the criteria of serological titres of $1 / 160$ or more, this almost certainly underestimated the incidence of $M$ pneumoniae infection for various reasons. The complement fixation titre is diagnostic in only $80 \%$ of cases ${ }^{11}$ children with mild respiratory symptoms were less likely to have been investigated, and not all patients presenting to the hospital were screened with a second blood sample.

The incidence of asthma found in this present study is higher than the incidence of asthma in the childhood population of Australia. ${ }^{12}$ The findings also suggest that $M$ pneumoniae affects bronchomotor tone, even in non-asthmatic children. Bronchodilators may, therefore, have a therapeutic role in acute $M$ pneumoniae infection, even in nonasthmatic children. Wheezing in asthmatic children in response to $M$ pneumoniae infection has been well described before, ${ }^{13}{ }^{14}$ but transient bronchial lability after $M$ pneumoniae infection has only been described in adults. ${ }^{34}$

The present study showed that at three years, even in the non-asthmatic child, three parameters of lung function were significantly less than control values. Another study ${ }^{6}$ has also documented functional abnormality in a similar group of children followed for a variable period of time. In neither study, however, were the control groups randomly selected and the differences in lung function could have been due to other factors such as social class and parental smoking. Despite these limitations, the findings may indicate either longstanding damage due to $M$ pneumoniae or that children with pre- existing functional abnormalities present with more serious illness.

This study confirms the lack of evidence for substantial antibiotic effectiveness in children with $M$ pneumoniae. This is in agreement with conclusions previously drawn ${ }^{7}$ despite benefits previously shown in adult patients. ${ }^{8} 1516$ The reasons for these conflicting findings may reflect the time of beginning antibiotics or differences in severity of infection between studies. Lack of erythromycin response is unlikely to have been caused by the emergence of resistant strains ${ }^{10}$ but may, in part, be due to the partial immune suppression that has been shown to follow infection ${ }^{17}$ in children. No significant effects of treatment upon pulmonary function three years after infection were evident, but numbers in the groups were small.

We also speculate that some of the morbidity in $M$ pneumoniae infection may be due to secondary infection with Haemophilus influenzae ${ }^{18}$ as two children in this study had this organism isolated from bronchial aspirates. Response to antibiotics may, therefore, be a function of treatment of this secondary infection in some cases.

We conclude that despite the above mentioned defects of this study the incidence of asthma in children presenting to a paediatric hospital with $M$ pneumoniae infection was greater than expected in a normal population. In some non-asthmatic children $M$ pneumoniae infection causes wheezing, acutely, and prolonged bronchial lability.

This study indicates that erythromycin, if given early during the course of infection, may modify at least part of the acute illness, although there seems to be no major benefit of appropriate treatment upon long term pulmonary function.

This study also suggests that $M$ pneumoniae may lead to pulmonary damage or may affect subsequent pulmonary development several years after the initial infection. Clearly, properly controlled long term trials are essential if these findings are to be verified. 


\section{References}

' Eaton MD, Meiklejohn G, Van Herick W. Studies on the etiology of primary atypical pneumonia: I. a filterable agent transmissable to cotton rats, hamsters and chick embryos. $J$ Exp Med 1944;79:649-68.

2 Marmion BP, Goodburn GM. Effect of an organic gold salt on Eaton's primary atypical pneumonia agent and other observations. Nature 1961;189:247-8.

${ }^{3}$ Bervan H. Studies on the cardiopulmonary function in the post infectious phase of 'atypical' pneumonia. Acta Med Scand 1962;382(suppl):7-47.

${ }^{4}$ Dierckx JP, Gillard C. The results of pulmonary function tests in patients infected with Mycoplasma pneumoniae. Infection 1976:1(suppl):68-70.

5 Kjellman B. Pulmonary function in children with Mycoplasma pneumoniae pneumonia. Infection 1976;1(suppl):71-4.

6 Mok JYQ, Waugh PR, Simpson H. Mycoplasma pneumoniae infection. A follow up study of 50 children with respiratory illness. Arch Dis Child 1979;54:506-611.

7 Stevens D, Swift PGD, Johnston PGB, et al. Mycoplasma pneumoniae infections in children. Arch Dis Child 1978;53: $38-42$.

${ }^{8}$ Kingston JR, Chanock RM, Muffson MA, et al. Eaton agent pneumonia. JAMA 1961;176:118-123.

${ }^{y}$ Shames JM, George RB, Holliday WB, et al. Comparison of antibiotics in the treatment of mycoplasmal pncumonia. Arch Intern Med 1970;125:680-4.

10 Jao RL. Finland M. Susceptibility of Mycoplasma pneumoniae to 21 antibiotics in vitro. Am J Med Sci 1967;253:639-50.
"Feizi T, Maclean H, Sommerville RG, et al. Studies on an epidemic of respiratory disease caused by Mycoplasma pneumoniae. Br Med J 1967;i:457-60.

12 Williams HE, McNichol KN. Prevalence, natural history and relationship of wheezy bronchitis and asthma in children. An epidemiological study. $\mathrm{Br}$ Med $J$ 1969;iv:321-5.

${ }^{13}$ Berkovich S, Millian SJ, Snyder RD. The association of viral and mycoplasma infections with recurrence of wheezing in the asthmatic child. Ann Allergy 1970;28:43-9.

${ }^{14}$ Henderson FW. The etiologic and epidemiological spectrum of bronchitis in pediatric practice. J Pediatr 1979;95:183-90.

15 Rasch JR, Mogabgab WF. Therapeutic effect of erythromycin on Mycoplasma pneumoniae pneumonia. Antimicrob Agents Chemother 1965;5:693-9.

${ }^{16}$ Shames JM, Detal GM. Comparison of antibiotics in the treatment of mycoplasmal pneumoniae. Arch Intern Med 1970;125:680-4.

17 Sabato AR, Cooper DM, Thong YH. Transitory depression of immune function following Mycoplasma pneumoniae infection in children. Pediatr Res 1981;15:813-6.

${ }^{18}$ Stadel BV, Foy HM, Nuckolls JW, et al. Mycoplasma pneumoniae infection followed by Haemophilus influenzae pneumonia and bacteremia. Am Rev Respir Dis 1975;112:131-3.

Correspondence to Dr A J Martin, Pulmonary Medicine Unit, The Adelaide Children's Hospital Inc. North Adelaide SA 5006, Australia.

Received 16 July 1984

\section{British Paediatric Association}

\begin{tabular}{rrr}
\multicolumn{4}{c}{ Annual meetings } \\
1985 & $16-20$ April & York University \\
1986 & $15-19$ April & York University \\
1987 & $7-11$ April & York University
\end{tabular}

56th Annual Meeting

The programme for the Annual Meeting contains abstracts for all the papers presented, including Plenary, Poster, and Group sessions. Copies of the programme are available at $£ 3$ from: The British Paediatric Association, 23 Queen Square, London WC1. 